\title{
Resectable Malignant Neoplasm
}

National Cancer Institute

\section{Source}

National Cancer Institute. Resectable Malignant Neoplasm. NCI Thesaurus. Code C150602.

Malignant neoplasm that is amenable to surgical resection. 